RUNNING HEAD: TECHNOLOGY ADOPTION IN HEALTHCARE DELIVERY

Adoption of technological innovation in healthcare delivery: A social dynamic perspective

\author{
Jennifer Wong ${ }^{1}$, \\ Katharina Näswall ${ }^{1}$, \\ Fleur Pawsey ${ }^{1}$, \\ J. Geoffrey Chase ${ }^{2}$, \\ Sanna Malinen ${ }^{3}$ \\ ${ }^{1}$ School of Psychology, Speech and Hearing, \\ ${ }^{2}$ Department of Mechanical Engineering \\ ${ }^{3}$ Department of Management, Marketing and Entrepreneurship \\ University of Canterbury \\ Christchurch \\ New Zealand
}

Corresponding author:

Jennifer Wong, jennifer.wong@ canterbury.ac.nz 


\begin{abstract}
Technological advancements are vital for improving the capacity of the health system to deliver health and wellbeing benefits to individuals. Despite significant financial investments in technological innovations in healthcare, patients are reported to benefit from only $30-50 \%$ of new healthcare technologies. We propose that some of the challenges of technology adoption are related to human factors, and specifically to social dynamics in healthcare workplaces, and that organisational psychology perspectives can facilitate our understanding of how to manage these dynamics. The aim of the present paper is to present a framework (TECH-ISM) to empower medical decision-makers to become innovation drivers by influencing the social dynamics are within medical workplaces. Our framework is based on an overview of research on technology adoption, where we highlight the impact of relational and social factors, and how adoption is affected by key relationships in healthcare delivery workplaces. We conclude our paper with a discussion of how medical decision-makers can socialise new technology into the workplace, and the importance of managing these social dynamics over time.
\end{abstract}




\section{Adoption of technological innovation in healthcare delivery: A social dynamic perspective}

Technological innovations increasingly redefine how societies function. In healthcare, technological advancements are vital for improving the capacity of the health system to deliver health and wellbeing benefits to individuals (Alexander et al., 2012; Baumol, 2012; Glorioso \& Subramanian, 2014; Halpern, 2009; Lamm, 1988; Robinson et al., 2014; Wutzke et al., 2016). It is no surprise healthcare technology is a near trillion-dollar per year industry with tangible individual and societal impacts (Facts \& Factors, 2021; Statista, 2018; Vautier, 2019). To illustrate, US \$9.1b alone was invested in healthcare technology start-ups in 2020, a 19\% increase from 2019 (Ministry of Health, 2020). This investment trend is anticipated to grow, and the innovations are expected to diversify to address future needs and demands.

Despite these advancements, patients are reported to benefit from only $30-50 \%$ of new healthcare technologies (Grol, 2001; Schuster et al., 2005). This disappointing rate suggests at least half of innovations fail to be successfully adopted in healthcare workplaces, even after being clinically validated in earlier development stages. While the actual adoption failure rates vary across types of medical services and user groups (Adler-Milstein et al., 2014; McGinn et al., 2011), it is clear the technology implementation stage is fraught with complex challenges. Indeed, barriers are faced by healthcare staff (i.e., the nurses, physicians) and healthcare management (i.e., unit managers, chief medical officers). Lack of government priority (i.e., funding) to support healthcare innovation can set up new technologies for failure (Little, 2021). Failed adoptions can pose not only risks to patient safety but also to the reputation of the healthcare system, which can then compromise public trust (Cairns et al., 2013).

There are both direct and indirect costs when technology adoption fails in healthcare. Direct costs concern the wasted capital, infrastructure, time, and expertise utilised in the 


\section{TECHNOLOGY ADOPTION IN HEALTHCARE DELIVERY}

technology development stage, and the loss in unrealised patient health benefits. Indirect, yet insidious, costs of failed technology adoption relate to its implications for economic and societal losses. Specifically, without successful adoptions of new technology, the healthcare delivery sector loses out on potential growth in the provision of care, which can accelerate the already serious inequity in access and outcomes, particularly for at-risk and socioeconomically disadvantaged communities in society (Ministry of Health, 2019; Marriott, 2014). In short, successful healthcare technology adoption is of paramount importance because it is indicative of the wealth and health of a nation (Garber et al., 2014).

\section{Overall Aim}

While the research on the technology adoption issue in healthcare is extensive, findings to date have limited practical value for helping healthcare professionals overcome adoption challenges. Indeed, the problem still exists, indicating a need for translational sciences and practices, specifically catered for medical decision-makers, to improve the adoption and uptake of clinically and economically validated technologies. We propose some of the challenges of technology adoption are related to human factors (Chase et al., 2008), specifically the social dynamics in healthcare workplaces. We believe these social dynamics are within medical decision-makers' scope of professional responsibility to develop a better understanding of them, and, within their control, to directly manage them.

The five sections in this paper present an organisational psychology perspective on the technology adoption problem in the healthcare delivery sector, with the aim to empower medical decision-makers to become innovation drivers. The first two sections are an overview of research on technology adoption to highlight the impact of relational and social factors (Part 1), followed by technology adoption specifically in the context of healthcare delivery (Part 2). In the last three sections, we present a framework for $\underline{i}$ dentifying, socialising, and $\underline{\text { managing }}$ 


\section{TECHNOLOGY ADOPTION IN HEALTHCARE DELIVERY}

(TECH-ISM) the social dynamics when preparing for and carrying out the implementation of new technology. We highlight three key relationships in healthcare delivery workplaces influencing technology adoption (Part 3), discuss how medical decision-makers can socialise new technology into the workplace (Part 4), and the importance of managing these social dynamics over time (Part 5).

For this paper, we define technology adoption as the integration and use of new technology in a workplace, and technology acceptance as to how staff members come to accept and use a technology (i.e., the first step of technology adoption). We will focus our discussion specifically on healthcare delivery technologies, and primarily on its implementation phase. Our discussion acknowledges the importance of person-centered design (Clark et al., 2019). While the Tech-ISM Framework assumes technical factors around usability, such as security, languages, and universal standards are addressed at the development stage (as reviewed in (Kruse et al., 2016; McGinn et al., 2011; Schreiweis et al., 2019)), we will suggest how medical decision-makers and professionals can engage with developers to enable this outcome (Greenhalgh et al., 2017).

\section{Part 1: Overview of Technology Adoption}

The introduction of new technology in any workplace symbolises a change in the status quo of attitudes (i.e., developing thoughts, feelings, and judgements of the new technology) and behaviours (i.e., integrating the new technology into their existing ways of working). Change requires energy and effort; the motivation for changing needs to offset this anticipated cost (Rogers et al., 2014). In relation to adopting new technologies, when the need and conviction for it is obvious, and when its benefits can be immediately evident, the motivation to adopt will be greater (Kubr, 1996). Aside from seeing change as a cost, change can also be perceived as a threat to an employee's sense of identity around work and technology (Identity Process Theory; (Breakwell, 1988, 2015)), and resistance to the change is a reaction to cope 


\section{TECHNOLOGY ADOPTION IN HEALTHCARE DELIVERY}

with this threat. Resistance to technology adoption may manifest as emotions directed to the uncertainty (e.g., due to the fear of the unknown, dislike of surprises), internally (e.g., confidence, fear of failure, reluctance to deal with challenges), or towards the organisation (e.g., dislike of imposed change, dislike of change in established practices and habits and shift of power, lack of trust and respect of the person leading the change, failure of previous changes; (Gill, 2002; Kubr, 1996).

A variety of theoretical approaches have been used to understand why and how new technologies are adopted in workplaces. Each of these approaches prioritises a different aspect of technology depending on which discipline the theory stems from. Liberati et al. (2017) identified four main approaches (see Table 1): the engineering approach, which focuses on the interaction between technology and users; the cognitive-behavioural approach, which focuses on user's intentions to adopt technology; the organisational approach, which focuses on organisational and system influences at work; and the social approach, which focuses on the social context of technology. These multi-disciplinary efforts yield a rich array of lenses through which technology adoption problems can be understood.

\section{Table 1}

Technology adoption theoretical approaches (Liberati et al., 2017)

\begin{tabular}{lll}
\hline Theoretical approach & Focus & Example \\
\hline Engineering & $\begin{array}{l}\text { Interaction between } \\
\text { technology and users }\end{array}$ & $\begin{array}{l}\text { Usability (Triberti \& Riva, } \\
\text { 2015) }\end{array}$ \\
\hline Cognitive-behavioural & $\begin{array}{l}\text { Prediction of intention to } \\
\text { adopt a technology }\end{array}$ & $\begin{array}{l}\text { Unified Theory of } \\
\text { Acceptance and Use of } \\
\text { Technology (Venkatesh et } \\
\text { al., 2003) }\end{array}$ \\
& & $\begin{array}{l}\text { Organisational change } \\
\text { readiness (Holt et al., 2007) }\end{array}$ \\
\hline Organisational & $\begin{array}{ll}\text { Organisational barriers and } \\
\text { facilitators }\end{array}$ & $\begin{array}{l}\text { Normalisation Process } \\
\text { Theory (May et al., 2007) }\end{array}$ \\
\hline Social & $\begin{array}{l}\text { Acceptance determined by } \\
\text { social practices }\end{array}$ &
\end{tabular}




\section{TECHNOLOGY ADOPTION IN HEALTHCARE DELIVERY}

Despite the multiple approaches, successful technology adoption is typically operationalised using the cognitive-behavioral approach, which focuses primarily on the user's perspectives of technology. The two most common technology adoption measures used are from the Technology Acceptance Model (TAM; (Davis, 1989) and the Unified Theory of Acceptance and Use of Technology Model (UTAUT; (Venkatesh et al., 2003). Both models emphasise the importance of user's perceptions of the new technology's usefulness and ease of use. Later iterations of the TAM added in consideration for subjective norms, in that user's perceptions of peer opinions of the technology can influence their own opinions (Venkatesh \& Davis, 2000).

While these cognitive-behavioural models attempt to incorporate social aspects of technology adoption, critics maintain they have an overly simplified view of human and organisational change (Glass \& Li, 2010; Greenhalgh et al., 2017; Lee et al., 2003; Legris et al., 2003; Moray, 2000). The cognitive-behavioural models consider adoption as attitudes of one individual, which we argue is technically 'technology acceptance', the very first step towards technology adoption. This focus on individual's attitudes overlooks the significant impact of attitudes developed and shared by groups over time, and falls short of capturing the team-wide and organisational-wide integration necessary for genuine technology adoption in a workplace. Furthermore, the cognitive-behavioural models present a linear view of the process of implementing change in the workplace (Radin Umar et al., 2018) while change can be a dynamic, multi-stage process (Greenhalgh et al., 2004; Radin Umar et al., 2018), involving employees of different levels of readiness (Transtheoretical Model; (Prochaska \& Velicer, 1997)), where success in the earlier stages can influence the adoption rate in subsequent stages (Rogers et al., 2014). 


\section{Opportunity: Operationalising Technology Adoption as a Dynamic and Social Process}

The Diffusion of Innovation Theory, traditionally used to explain how novel ideas are spread within a social system, can help see technology adoption as a dynamically collective process. According to the Diffusion of Innovation Theory (Rogers et al., 2014), innovation is uptake by people of varying degrees of readiness across different stages of implementation (see Figure 1). Where adoption typically fails is at 'The Chasm' - the transition point between the 'early adopters' group and the 'early majorities' group — at which the understanding of an innovation's functional (e.g., costs versus gains) and emotional values (e.g., the effort to uptake; (Shah \& Rothstein, 2020)) starts to vary due to differences in appetite for risk and social susceptibility of these two groups (Moore \& Benbasat, 1991). Early adopters are more receptive to adopting innovation due to high risk and payoff mentality; early majorities are typically risk averse and are more likely to adopt innovation via social influence and validation (e.g., peer endorsement).

While this classification of adopters provides a basic perspective on technology adoption in a workplace, the key takeaways are: 1) there are different motivations and risk perceptions for the adoption of new ideas; and 2) strategies accounting for the power of social influence can help gain momentum towards organisation-wide uptake of new technology (i.e., overcome 'The Chasm'). For example, innovations that undergo reinvention to further suit users beyond the initial adopters are more likely to be successful (Vaidyanathan et al., 2019). Bayesian modelling predicts that the addition of early adopters within a social system can increase the likelihood of adoption by 15-47\% (Hao et al., 2018). Though current innovation implementation approaches focus on discerning the early adopters from the late adopters, more research on the socially impressionable early majority group and their motivation for innovation uptake is necessary in order to overcome 'The Chasm'. 


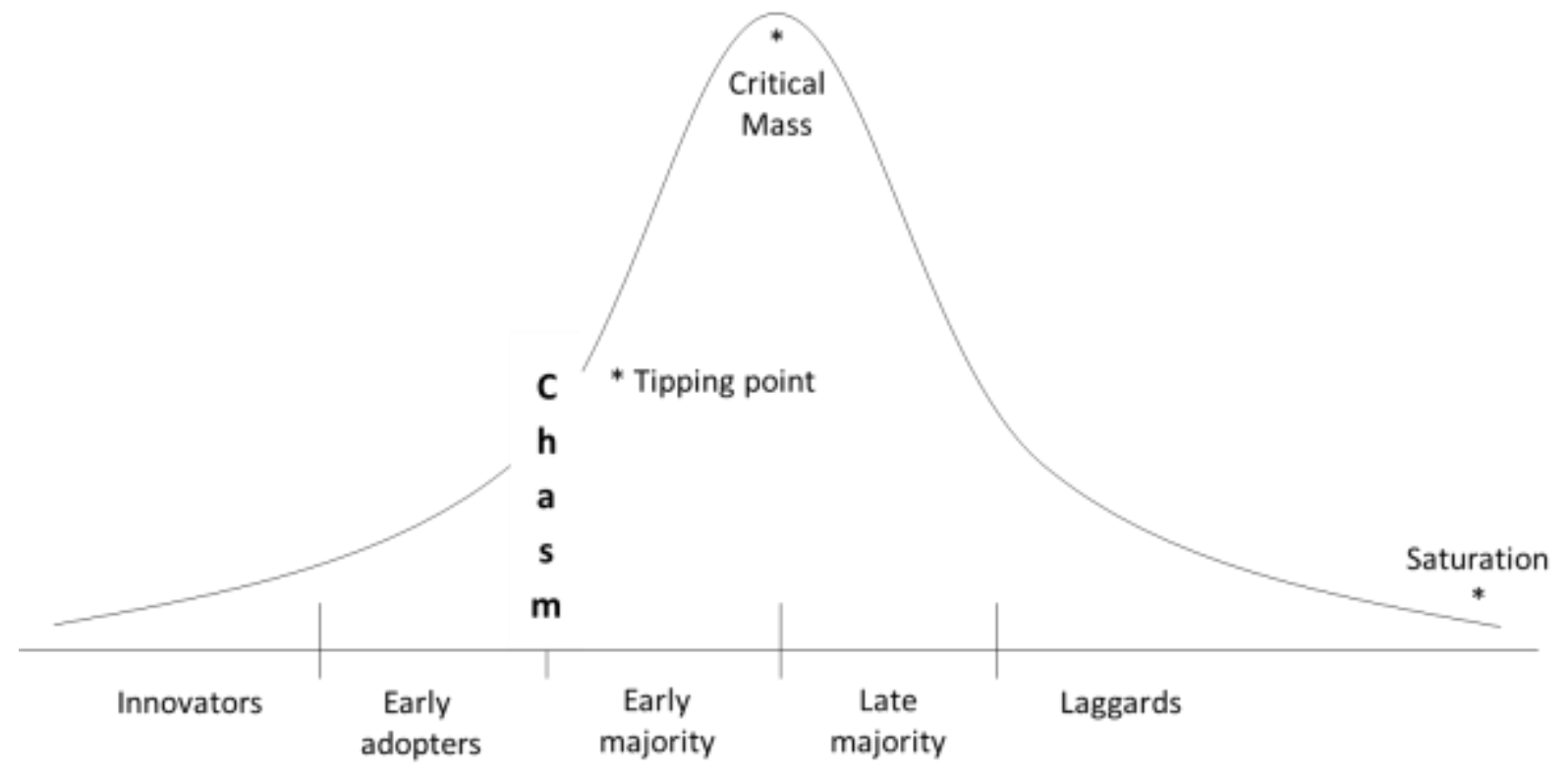

Figure 1. Diffusion of Innovation (Roger, 2014)

\section{Part 2: Technology Adoption within the Healthcare Delivery Context}

To consider technology adoption in healthcare delivery settings requires first an understanding of the defining characteristics of its work context. Healthcare personnel work as highly task-interdependence teams (Sundstrom et al., 1990), in which team members have clearly defined roles and perform specific job tasks within their professional boundaries (Andreatta, 2010). The ability of individual staff members to perform their designated tasks is critical for the overall team's performance (Taplin et al., 2015). This interdependency in tasks is also reflected in the scope of responsibility, as individual staff members can be responsible to several team members in addition to formal supervisory staff members (Apker et al., 2005; Miller et al., 2000).

The healthcare delivery work context is a time-sensitive, high-stress, high-stakes environment. Decisions about patient health often have to be made quickly and accurately (Hughes et al., 2016). In this work environment, teams rely on conformity through routine practices and hierarchical decision-making to maintain performance and safety standards, typically denoted protocolized care (e.g., (Bogerd et al., 2019; Coz Yataco et al., 2017; Duggal 


\section{TECHNOLOGY ADOPTION IN HEALTHCARE DELIVERY}

et al., 2021; Goodwin et al., 2016; Morris, 2003; Schipper et al., 2010)). Teams revert to a hierarchical chain-of-command and expert opinions to make decisions about patient health (Hollenbeck et al., 2012). However, when certain members of the team have more control over decision-making than others, it can exacerbate existing hierarchies and result in power differences in the team's structure (Green et al., 2017). For example, physicians can be in a better position to object to accepted best practices or protocols without consequences (Gardezi et al., 2009; Malloy et al., 2009; McBride-Henry \& Foureur, 2007; Schwappach \& Gehring, 2014) than nursing staff (Garon, 2006).

The introduction of new technology in a healthcare workplace requires staff to reconsider their work processes and relearn it to the point of becoming routine, both of which requires effortful attention and increases the cognitive load in an already high-stress and highdemands work environment (i.e., increase clinical burden; (Carayon \& Gürses, 2005; Chase et al., 2008; Gurses \& Carayon, 2009; Sinuff et al., 2007; Tang et al., 2007)). In addition, the process of adoption can expose staff and patients to the risk of errors, which can have costly consequences and a negative impact on professional identity (e.g., loss of patient lives, reduced quality of care). Given the interdependency of the ways of working, new technology loses clinical effectiveness as compliance falls from 100\% (Chase et al., 2008) or, in other words, when the technology is only accepted by some staff but not others, its positive impacts can be negated. While staff may conform to the behavioural expectation to use the new technology, sustainable technology adoption requires a change in the underlying attitudes towards the new technology and any resulting changes in practice. Thus, the hierarchical structure of a healthcare workplace can hinder genuine adoption, both directly and less intentionally. Successful technology adoption thus needs to consider these defining features of healthcare delivery's organisational context. 


\section{Overview of Barriers and Enablers of Technology Adoption in Healthcare Delivery}

In the last 20 years, extensive research has been conducted to illuminate the barriers and enablers of successful technology adoption in healthcare delivery. Systematic reviews have organised this vast body of findings in meaningful ways, from conceptualising adoption factors at micro-, meso-, and macro- levels (e.g., (Chaudoir et al., 2013), to examining factors across different types of technology (e.g. (Gagnon et al., 2012; Greenhalgh et al., 2017) and healthcare job roles (e.g., (Koivunen \& Saranto, 2018; McGinn et al., 2011). Across these reviews, the categorisation of adoption barriers and enablers fall into individual, social, and organisational factors (see Table 2 for a summary).

\section{Table 2}

Summary of the enablers and barriers to technology adoption in healthcare identified in systematic reviews

\begin{tabular}{|c|c|c|}
\hline Type of factor & Barriers & Enablers \\
\hline Individual & $\begin{array}{l}\text { Increased workload and time } \\
\text { for integration (Gagnon et al., } \\
\text { 2012; Lluch, 2011; McGinn et } \\
\text { al., 2011; Schreiweis et al., } \\
\text { 2019) } \\
\text { - Lack of accessibility to the } \\
\text { new technology (Gagnon et } \\
\text { al., 2012) } \\
\text { - Lack of trust in the new } \\
\text { technology (Lluch, 2011; } \\
\text { Schreiweis et al., 2019) } \\
\text { - Fear of changes at work } \\
\text { (Koivunen \& Saranto, 2018) } \\
\text { - Fear of being replaced by the } \\
\text { new technology (Koivunen \& } \\
\text { Saranto, 2018) } \\
\text { Disinterest, misgivings of the } \\
\text { new technology (Koivunen \& } \\
\text { Saranto, 2018) } \\
\text { Technophobia, the fear of } \\
\text { general technology (Koivunen } \\
\text { \& Saranto, 2018) }\end{array}$ & $\begin{array}{l}\text { Previous experience, skills, and } \\
\text { familiarity with general } \\
\text { technology (Gagnon et al., } \\
\text { 2012; Koivunen \& Saranto, } \\
\text { 2018; McGinn et al., 2011; } \\
\text { Schreiweis et al., 2019) } \\
\text { - Positive learning experience on } \\
\text { how to use the new technology, } \\
\text { viewing it as an opportunity to } \\
\text { upskill (Koivunen \& Saranto, } \\
\text { 2018) } \\
\text { Perceived benefits of using the } \\
\text { new technology (Kruse et al., } \\
\text { 2016) } \\
\text { Perceived ease of use of the } \\
\text { new technology (Gagnon et al., } \\
\text { 2012) } \\
\text { Motivation to uptake the new } \\
\text { technology (Gagnon et al., } \\
\text { 2012; McGinn et al., 2011) }\end{array}$ \\
\hline
\end{tabular}




\begin{tabular}{|c|c|c|}
\hline & $\begin{array}{l}\text { Perceived productivity loss } \\
\text { (Kruse et al., 2016; McGinn et } \\
\text { al., 2011) }\end{array}$ & \\
\hline Social & $\begin{array}{l}\text { Negative feelings related to: } \\
\text { - } \quad \text { Perceived detriment to patients } \\
\text { outcomes and hindrance of the } \\
\text { staff-patient interactions } \\
\text { (Gagnon et al., 2012; } \\
\text { Koivunen \& Saranto, 2018; } \\
\text { McGinn et al., 2011) } \\
\text { - Colleagues' negative attitudes } \\
\text { resisting the new technology } \\
\text { (Gagnon et al., 2012; } \\
\text { Greenhalgh et al., 2017) } \\
\end{array}$ & $\begin{array}{l}\text { Positive feelings related to: } \\
\text { - Perceived benefits to patients } \\
\text { and enrichment of the staff- } \\
\text { patient interactions (Gagnon et } \\
\text { al., 2012; Koivunen \& Saranto, } \\
\text { 2018; McGinn et al., 2011) } \\
\text { - Colleagues' positive attitudes } \\
\text { accepting of the new } \\
\text { technology (Gagnon et al., } \\
\text { 2012; Greenhalgh et al., 2017) }\end{array}$ \\
\hline Organisational & $\begin{array}{l}\text { Incompatibility of technology } \\
\text { with work practices and tasks } \\
\text { (Gagnon et al., 2012; Kruse et } \\
\text { al., 2016; Lluch, 2011; } \\
\text { Schreiweis et al., 2019) } \\
\text { - Depersonalisation of health } \\
\text { delivery and changing work } \\
\text { culture from the introduction } \\
\text { of the new technology (Lluch, } \\
\text { 2011) } \\
\text { Lack of training and support } \\
\text { for integrating the new } \\
\text { technology (Kruse et al., 2016; } \\
\text { Schreiweis et al., 2019) }\end{array}$ & $\begin{array}{l}\text { - Increased productivity from } \\
\text { adoption (Gagnon et al., 2012; } \\
\text { Koivunen \& Saranto, 2018) } \\
\text { - Support from management to } \\
\text { uptake the new technology } \\
\text { (Gagnon et al., 2012) } \\
\text { - Structured healthcare systems } \\
\text { (Lluch, 2011) and leadership } \\
\text { guiding the introduction of the } \\
\text { new technology (Ingebrigtsen } \\
\text { et al., 2014) }\end{array}$ \\
\hline
\end{tabular}

Much of this research in Table 2 focuses on cognitive-behavioural factors relating to individual employees: their current perceptions of the new technology, and their previous experience with technology in general. Current perceptions are the thoughts that form when employees start interacting with the new technology (e.g., usefulness; (Kruse et al., 2016), motivation to use; (McGinn et al., 2011); trust in technology; (Lluch, 2011)). On the other hand, the factors relating to past experience with previous technologies (e.g., skills acquired from previous use of similar technology, familiarity with similar technology; (Gagnon et al., 2012; Koivunen \& Saranto, 2018; McGinn et al., 2011; Schreiweis et al., 2019)) — while formed prior to new technology's introduction — can influence how receptive employees are 


\section{TECHNOLOGY ADOPTION IN HEALTHCARE DELIVERY}

to technology-related changes in the workplace. Thus, staff's history of technology use is also important to take into account.

Aside from individual current and past perceptions, there are emotions, such as fear, reluctance, and disinterest towards the technology, which also impact technology adoption (Koivunen \& Saranto, 2018). Fear, in particular, is commonly identified as a barrier and can manifest in different forms: fear of the technology itself (technophobic), fear of changing environment (e.g., changes at work, (Koivunen \& Saranto, 2018; Kruse et al., 2016)), culture and norms (e.g., fear of depersonalisation of healthcare, (Lluch, 2011)), and self-identity (e.g., fear of being replaced by technology, undermined credibility, impact on professional identity; (Koivunen \& Saranto, 2018)). Fear, and emotions in general, are important to consider as factors affecting technology adoption.

\section{Opportunity: Harnessing Collective Attitudes for Healthcare Technology Adoption}

The trend of focusing on cognitive-behavioural approaches and individualistic factors in general technology adoption research is also reflected in healthcare-specific technology adoption. Given the hierarchical structure of healthcare delivery units, the high interdependency of its teams, and the need for $100 \%$ compliance of new technology for it to perform with optimal clinical effectiveness, we argue social approaches may be more suitable for understanding technology adoption in the healthcare delivery context.

For instance, May et al. (2018) Normalisation Process Theory conceptualises technology adoption as a collective process of developing new norms and practices around the new technology. Thoughts and feelings towards technology are no longer confined to within a singular individual, but can be influenced by and negotiated across individuals and groups (Greenhalgh et al., 2017; May \& Finch, 2009). Socio-relational phenomena in healthcare pertaining to technology adoption can be observed as group-based decision-making on 


\section{TECHNOLOGY ADOPTION IN HEALTHCARE DELIVERY}

adopting change (Industrial adoption model; (Ozanne \& Churchill Jr, 1971)), how technology affects staff-patient relationship (Normalisation Process Theory; (May \& Finch, 2009)), and how technology affects different social standings of job positions and professional groups (Strong Structural Theory; (Greenhalgh \& Stones, 2010)). Social approaches to technology adoption also consider how the new technology affects the organisational context, such as the interaction between people, practices, and division of labour (Murray et al., 2010).

Our Table 2 revealed attitudes towards technology adoption could also have an emotional component. Emotions are understudied relative to cognitive perceptions in attitudinal research (e.g., change readiness; (Rafferty et al., 2013; Trafimow \& Sheeran, 1998), yet emotions can be more influential for decision-making at times of heightened stress and uncertainty by standing in as substitutes for information (Dimoff \& Kelloway, 2019; Kozlowski et al., 2017; Loewenstein et al., 2001; Ness \& Klass, 1994). This is evident in the context of healthcare (Kozlowski et al., 2017; LeBlanc et al., 2015; Marcum, 2013), where emotions can play a significant part in the assessment of risk (Chase et al., 2021). Therefore, understanding how attitudes, particularly emotions, about new technology are created and spread across individuals and groups can be valuable for medical decision-makers wanting to optimise technology uptake.

\section{Part 3: Tech-ISM - Identifying Workplace Social Dynamics of Technology Adoption}

To integrate the opportunities identified so far, we present a framework supporting medical decision-makers in understanding and managing the social enablers of technology adoption, specifically, the social dynamics around adoption attitudes. We define workplace social dynamics as a social feedback loop between the individual and other groups of people in the work system. We highlight three key relationships within a healthcare context that are social feedback loops: staff and 1) their team members; 2) their supervisors; and 3) their 


\section{TECHNOLOGY ADOPTION IN HEALTHCARE DELIVERY}

patients (see Figure 2). Taken together, while an individual staff member may have a predisposed inclination towards technology (history with technology), attitudes are further constructed when they engage with or hear of their team members, supervisors, and patients' opinions of the new technology. Adoption attitudes are akin to a sense of readiness for change, which is a cognitive and emotional inclination to "accept, embrace, and adopt a particular plan to purposefully alter the status quo" (Holt et al., 2007); pp. 235)). In what follows, we draw from social and organisational psychological sciences to illustrate how adoption attitudes are formed and spread across these three relationships.

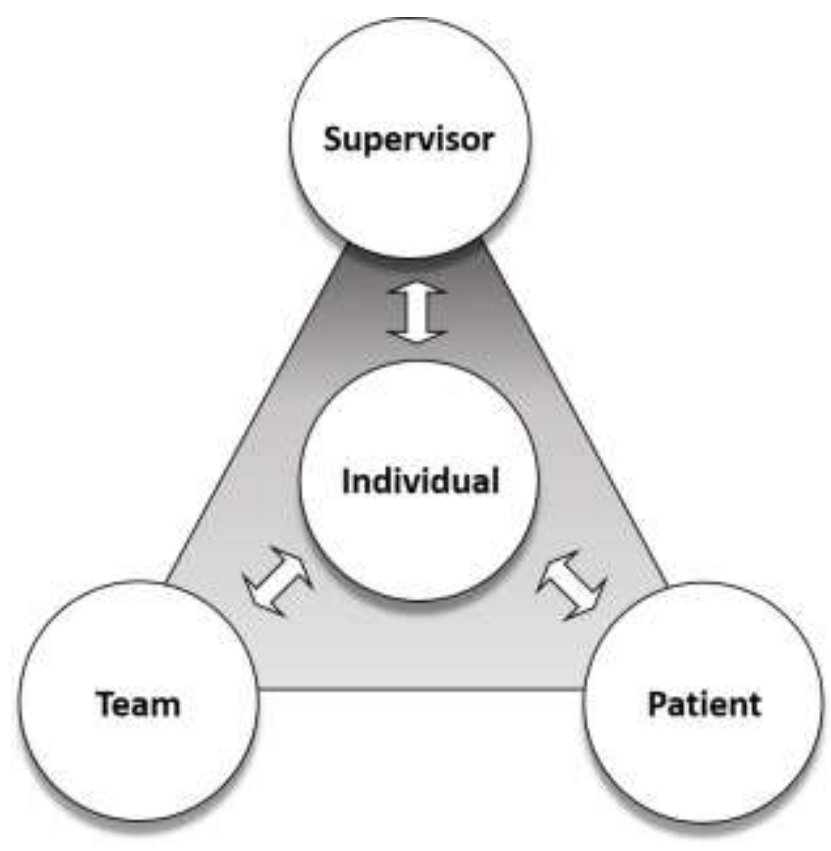

Figure 2. The three social feedback loops (social dynamics) of technology adoption in healthcare.

New attitudes can form through social learning, in which an individual learns by observing, modelling, and imitating other's behaviours (Bandura \& McClelland, 1971; Rogers et al., 2014). As a result of social learning, two processes may occur, the first of which is social contagion, in which similar attitudes spread within a group (Barsade \& Gibson, 2007; Bartel 


\section{TECHNOLOGY ADOPTION IN HEALTHCARE DELIVERY}

\& Saavedra, 2000; Foulk et al., 2016; Hatfield \& Cacioppo, 1994; Totterdell, 2000). An individual employee may observe and implicitly 'take on' their colleague's subtle expression of anxiety when using the new technology for the first time (e.g., mirroring the shallow and rapid breathing, furrowed brow, tense body posture; (Levenson, 1996)). The second process that may occur as social learning is sense-making, in that the group, through interactions with each other, come towards a collective meaning for the new technology (an unknown) that fits within their existing (and known) work by negotiating new norms and expectations (Brooks et al., 2015; George \& Jones, 2001; Maitlis \& Christianson, 2014; May \& Finch, 2009; Weick, 1995). For this reason, criticism of new technology shared openly can be damaging for technology adoption, because staff members consider collective attitudes in forming their own impressions of the technology.

Social learning is framed primarily as a cognitive process (Brooks et al., 2015), yet emotions can have a role in influencing the motivation for an individual to engage in this process. For example, emotions can affect the likelihood of an individual being open to other point of views (Steigenberger, 2015). Negative emotions (such as fear) may make a staff member reluctant to work as a group, or to accept others' acceptance of the technology, thus reducing compliance rate, clinical efficiency, and hindering technology adoption. Positive emotions can aid technology adoption by enabling pro-group attitudes (Steigenberger, 2015). We now elaborate on how these three types of social dynamics in a healthcare workplace can facilitate the diffusion of attitudes about the new technology. In the discussion below, we focus on the rate that perceptions and emotions for, or against, the new technology are constructed and spread.

\section{Team Social Dynamics}

We begin with the relationship between an individual staff member and their team. Since healthcare staff are required to work interdependently as a team to deliver patient care 


\section{TECHNOLOGY ADOPTION IN HEALTHCARE DELIVERY}

(Sundstrom et al., 1990), these social interactions make up the job and are most likely to involve the new technology. As a result, the individual-team social dynamic provides ample opportunities for social learning to take place. Indeed, how colleagues perceive and interact with the new healthcare technology are consistently identified to be key drivers of an individual's adoption (Gagnon et al., 2012).

Individual-team social dynamic can also dictate how quickly new technology is adopted organisation-wide; the value of new technology increases for each additional adopter (Rogers et al., 2014) because as compliance increases so does the likelihood of its clinical efficiency (Chase et al., 2008). Acceptance by peers is considered to be the single most important factor for successful technology adoption (Greenhalgh et al., 2017). Hence, staff members who first tried the new technology will be observed closely by the rest of the team, and the first teams to adopt the technology will be observed closely by the rest of their unit.

Several characteristics of the team could enhance their social dynamics. Team cohesion - an individual's attraction to their team (Seashore, 1954)-dictates how likely the individual would participate in team-related activities and behaviours (Salas et al., 2015). Therefore, the more cohesive the team the more opportunities they have to engage in conversations that serve to derive a shared meaning of the new technology. While role hierarchy within healthcare teams can negatively impact team cohesion, cohesion can be fostered through bonding over team tasks, social relationships, sense of belonging, sense of pride, and loyalty to the team in the face of challenges (Salas et al., 2015).

The similarity of team members and team size also matters. The spread of similar attitudes is more likely amongst team members with similar characteristics (e.g., gender; (Torrente et al., 2013) and the rate of social contagion is faster in smaller teams (Totterdell et al., 1998). Additionally, the rate of adoption is amplified by the extent of conformity in healthcare teams. Since conformity signifies performance and safety standards, once a new 


\section{TECHNOLOGY ADOPTION IN HEALTHCARE DELIVERY}

technology has been accepted (or rejected) by a few members, the rest of the team will likely follow suit.

\section{Patient Social Dynamics}

The capacity to provide high-standard quality of care is a core value in healthcare professionals (Jager et al., 2016), especially for front-line workers, such as nurses (Ko et al., 2018). This point suggests a sense of professional pride and identity is integral to individuals who commit to a career in healthcare delivery (Allen, 2014; Spehar et al., 2015; Vikström \& Johansson, 2019). Therefore, the staff-patient relationship may be the most meaningful social dynamic of the three and is unique to the healthcare sector.

Much of this identity is developed through social interactions with patients, and how they affect the staff's own sense of professional efficacy (Jones et al., 2016; Sommaruga et al., 2017). In fact, the quality of the patient-staff relationship has an impact on patient-care outcomes (Ciechanowski et al., 2001). In turn, patient benefits and satisfaction indicate the value of the new technology.

The staff-patient relationship can extend to patient family members, as well. In Aotearoa New Zealand, a patient's family and wider support networks influence the quality of outpatient care because it underlines Hauora Māori and a whānau/family-based vision of healthcare. Patients are asked if they want their whānua involvement in providing medical history background, or as support through the health system (Meihana Model; (Pitama et al., 2014; Pitama et al., 2007)). Patient perspectives, and those of their family, of the technology's benefits, applicability, and efficiency can influence staff's attitudes around the value of the new technology, thereby improving the likelihood of technology adoption (Koivunen \& Saranto, 2018; McGinn et al., 2011).

\section{Supervisor Social Dynamics}




\section{TECHNOLOGY ADOPTION IN HEALTHCARE DELIVERY}

The relationship between individual staff and multiple supervisory staff is significant in everyday healthcare delivery work, but it becomes more so in the event of a change like the implementation of new technology. In times of ambiguity, employees turn to their supervisors for cues to help them make sense of a change (Pearson \& Clair, 1998; Pescosolido, 2002). A supervisor who creates opportunities for their staff to discuss and reflect on the value of the new technology can guide the team towards adoption (Radin Umar et al., 2018).

However, in healthcare, the hierarchical structure can affect individual staffsupervisory staff social dynamic by hindering communication and collaboration (Baker et al., 2011), and can lower individual staff members' sense of voice, particularly those who are lowest in the hierarchy (Garon, 2012; Malloy et al., 2009; McBride-Henry \& Foureur, 2007; Schwappach \& Gehring, 2014; Sundqvist \& Carlsson, 2014; Todorova et al., 2014). Thus, hierarchy can reduce the likelihood of individual staff members engaging in the opportunities supervisory staff create for social learning, which would negatively impact the rate of adoption.

Healthcare supervisory structures can be complex, particularly for large units. For example, a nurse may be supervised by the head nurse, on-call specialists, head of the unit, and also registrars. Moreover, the composite of the supervisory staff varies based on shift rotation schedules (Wildman et al., 2012). Physicians and nursing staff may have different approaches to the provision of care (Hollenbeck et al., 2012) and tension from the hierarchical structure of healthcare (Gergerich et al., 2019), and inconsistency and conflicting perspectives of the new technology can result in interprofessional conflict (Brown et al., 2011; Kim et al., 2017), which creates further ambiguity and stress for staff lower in the hierarchy. How unified the opinions are on a specific technology among senior supervisory staff can affect the attitudes of staff members and the rate of technology adoption. 


\section{TECHNOLOGY ADOPTION IN HEALTHCARE DELIVERY}

\section{Part 4: Tech-ISM - Socialising Technology Adoption in Healthcare}

Taken together, the adoption process consists of an exchange of attitudes within three key relationships: staff-team; staff-patient; and staff-supervisory staff. These three types of social dynamics make up the social structure (values, norms, roles, hierarchy) of the social system of a healthcare delivery workplace (Rogers et al., 2014). Below we outline how medical decision-makers can prepare for the introduction of new technology in consideration of this social structure. Specifically, we discuss three resources to invest in: communication channels; support for staff workload; and leadership development for all senior staff, from supervisory staff to medical decision-makers themselves.

\section{Enriching the Communications Channels}

Communication channels are links between people that enable them to exchange information and insight on the new technology. Communication channels are necessary for social learning because they raise awareness and visibility of the technology and its relative advantage (i.e., an improvement over previous technology; (Rogers et al., 2014)). These channels can be structural (e.g., emails), but also psychological (e.g., staff feels comfortable enough to voice concerns without negative consequences). Enriching communication channels can enable information exchange, social learning, and thereby adoption attitudes, to spread and be created.

According to DOI Theory (Rogers et al., 2014), structural communication channels can be formal (e.g., weekly team meetings) or informal (e.g., conversations at bedside). Formal channels tend to be set up for mass media and are the best means for spreading initial awareness of the new technology. Informal channels tend to be interpersonal channels, are considered to be more effective for diffusing new ideas (Rogers et al., 2014), and therefore should be maintained over the technology implementation period. Both forms of communication channels can be used amongst teams, with patients and their family members, and by 


\section{TECHNOLOGY ADOPTION IN HEALTHCARE DELIVERY}

supervisory staff to share the value of using the new technology (e.g., feedback on patient benefits and satisfaction; improvement in clinical efficiency). Given that team members and supervisory staff are in constant rotation, encouraging communication-particularly through informal channels - with new team compositions and between teams is crucial. Even minute comments, such as "My partner is so much happier these days since they started Treatment $Q$ " from a patient's family members can increase the value of the new technology if shared across the workplace and can increase the likelihood of organization-wide adoption.

Staff members with influence can also be 'super diffusors' of adoption attitudes as they are highly respected and connected in their social networks, and are considered to be opinion leaders within formal and informal communication channels (Cho et al., 2012; Greenhalgh et al., 2017; Rogers et al., 2014; van Deen et al., 2019). Opinion leaders can often be early adopters (or at times, early rejecters) of technology and peers look to them as role models, so strategically getting individuals of influence uniformly on board early to support and champion the innovation can help with organisation-wide adoption (Rogers et al., 2014; Westover, 2010). In healthcare, influential change champions are identified to demonstrate ownership of the change, resilience, good communication skills, and-for those who are supervisorsparticipatory leadership styles that involve others in decision-making about the change (Bonawitz et al., 2020). Aside from champions, individuals who are the social connectors between different teams can facilitate the diffusion of new ideas into the homogenous groups (Cho et al., 2012; Rogers et al., 2014). Clinical nursing specialists and nurse practitioners are roles that are change connectors, in that they bridge the hierarchy between physicians and nurses (Bakerjian, 2008; Kaasalainen et al., 2015).

\section{Workload Management}

The introduction of new technology in the workplace requires effortful reconsideration and relearning process, which can introduce additional workload to staff in a high-stress and 


\section{TECHNOLOGY ADOPTION IN HEALTHCARE DELIVERY}

high-demands work environment. Work overload and fatigue can result in errors (Carrez et al., 2019; Dimova et al., 2018), which can increase the clinical burden and compromise the quality of patient care (Chase et al., 2008). Since patient care is core to healthcare staff's professional pride and identity, medical decision-makers must invest in resources to support the implementation of any new technology as a precaution to preventing negative attitudes about the technology from forming. Specifically, the barrier of lack of time to commit to carrying through with implementation of new technology, to integrate, and to learn to use it must be addressed (Gagnon et al., 2012; Lluch, 2011; McGinn et al., 2011; Schreiweis et al., 2019). The barrier of high workload should also be addressed directly in introducing new technologies, as it prohibits the amount of time available to properly uptake a new technology.

There are two aspects of the new technology that can impact time and workload. The first is the compatibility of the new technology with existing ways of working (Rogers et al., 2014): How big of a behavioural change is expected before the new technology can be used? How much physical space, or change in physical space, is required to adequately house the new technology? High workload could result from the incompatibility of technology with work practices and tasks, redefining boundaries in job roles due to the new technology, and changing tasks and workflow to suit new technology (Gagnon et al., 2012; Kruse et al., 2016; Lluch, 2011; Schreiweis et al., 2019). Medical decision-makers can help with large discrepancies in compatibility by introducing organisational change policies to present or roll-out the new technology in small incremental stages. For example, prior to a physical move to a new hospital, a unit can introduce a communication tool meant to be used at the new space at the old hospital first to reduce the work load and the number of changes when the move occurs.

The second aspect to consider is the complexity of the new technology (Rogers et al., 2014): How difficult would the new technology be to adopt, particularly from the perspective of the individual with the least favourable history with technology? Organisational factors, 


\section{TECHNOLOGY ADOPTION IN HEALTHCARE DELIVERY}

such as training and support to uptake technology (Kruse et al., 2016; Schreiweis et al., 2019) and increased accessibility to information and material resources about the technology (Gagnon et al., 2012), can free up more time or reduction in current workload for adopting complex technology. Training and preparing staff for use of new technology (e.g., simulation to pilot aspects of the new technology; (Eastman \& McCarthy, 2012)) can minimizes risk to patient safety and increase insight into how the technology works, which can enhance trust (Ali et al., 2005; Carayon \& Gürses, 2005; Chase et al., 2008; Sinuff et al., 2007; Tang et al., 2007). These support resources can allow healthcare staff to maintain high-quality patient care delivery despite technology complexity, and promote pro-technology adoption attitudes and outcomes.

\section{Leadership Development for Supervisory Staff}

Overseeing a change in the workplace can be an intensive, disruptive event, and requires supervisory staff, senior management staff, and medical decision-makers to demonstrate commitment, ownership, and responsibility for change. So far, this commitment has been discussed in terms of willingness to invest resources. As the change progresses, peoplemanaging skills will be necessary to overcome challenges in social dynamics as supervisors have to make difficult decisions and hold people accountable for their responsibility in the change (Gill, 2002), all while still instilling hope in the success of the change. Therefore, for technology adoption to be successful, supervisory staff should be competent in both managing and leading staff through change. Leadership development can help flatten the hierarchy in healthcare workplaces, as it can be particularly important for nursing staff's sense of professional competency as they transition into a supervisory role (Miskelly \& Duncan, 2014).

Change management skills are required to handle the technical aspects of change (Kotter, 1995), one of which is effective communication - the right information to the right individual(s) at the right time. An effective change supervisor articulates a clear implementation plan (e.g., structure, training, address changes at work, and follow-up on 


\section{TECHNOLOGY ADOPTION IN HEALTHCARE DELIVERY}

progress; (Ingebrigtsen et al., 2014; Ness \& Klass, 1994; Rafferty et al., 2013; Whelan-Berry et al., 2003)), keeps relevant groups informed on the progress of change, and hold individuals accountable for the role they play in the change (Gill, 2002). Poor quality plans, and inconsistency in or delayed communications around change, can lead to misunderstanding, cynicism, unhelpful rumors about the change (Bordia et al., 2004; Reichers et al., 1997; Wanous et al., 2000), and team conflict (Hughes et al., 2016).

Supervisors also require the emotional skills to lead change (Kotter, 1995), and to offer individualised support to guide staff members towards adopting the change. Change leadership creates a positive learning culture in the workplace by fostering a sense of trust (Newton et al., 2015) and psychological safety (Ortega et al., 2014): a sense that individuals can freely express themselves without repercussions (Edmondson, 1999). While this outcome can be enabled with supervisors leading reflective team practices (e.g., debriefs after using new technology; (Bailie et al., 2020)), much of this relationship building underlies a respectful workplace, thereby precedes the implementation period and will continue long after a technology is adopted. An effective change supervisor can accurately recognise the emotions of others, and understand the significance of their own emotions in influencing adoption attitudes (Sanchez-Burks \& Huy, 2009). Positive emotion spread between supervisors and their teams can facilitate adoption-enhancing pro-social behaviours to help with adjusting to change, such as cooperation, constructive problem-solving, and resilience (Bono \& Ilies, 2006; Sommer et al., 2016; Sy et al., 2005).

Finally, much of the efficacy, motivation, and drive behind a leader in promoting technology adoption hinge on their own adoption of the technology. An effective change supervisor communicates a vision of what the new technology can achieve in a manner compelling to their employees (Rafferty et al., 2013). Without genuine acceptance, a leader will not be able to persuasively communicate the value of the new technology and weave a 


\section{TECHNOLOGY ADOPTION IN HEALTHCARE DELIVERY}

compelling vision for a new way of working. These values, motivation, and vision are more powerful if consistent amongst the supervisory staff because it provides a collective message of certainty during change (Gill, 2002), which demonstrates integrated and distributive leadership (Mckenzie \& Locke, 2014; Woods et al., 2004). Distributive leadership is fostered on a high culture of respect and trust, is driven by a collective sense of purpose and actions, and all members have an agreed-upon way to address and resolve conflict (Jones, 2014; Woods et al., 2004).

Implementing and monitoring technology adoption can take a toll on the leaders involved. The wellbeing of leaders is linked to their ability to exhibit behaviours constructive for change (e.g., visionary, transformative; (Kaluza et al., 2020)). Medical decision-makers should prioritize their own health and wellbeing, which means managing their own workload, receiving leadership development relevant to implementing change in the workplace (e.g., difficult conversations), working together and supporting each other at the managerial level, and taking time to recovery from a heightened work environment (Wong, yet to be published research). Leadership coaching throughout the change can help with attaining goals, problemsolving, resilience, and a lower likelihood of depression (Grant et al., 2009).

\section{Part 5: Tech-ISM - Managing Technology Adoption}

At this point, we identified three types of social dynamics in healthcare contributing to the development and spread of attitudes towards new technology, and we suggested three key resources to invest in for enabling successful socialisation of new technology into a healthcare workplace. In the final section of the Tech-ISM Framework (see Figure 3), we now turn to consider technology adoption as a dynamic temporal process. Introducing a new technology seldom is a concise event, the acceptance and adoption take place over time. In this section, we 


\section{TECHNOLOGY ADOPTION IN HEALTHCARE DELIVERY}

elaborate on medical decision-makers' role in managing technology adoption, not just during the implementation period, but also leading up to it.

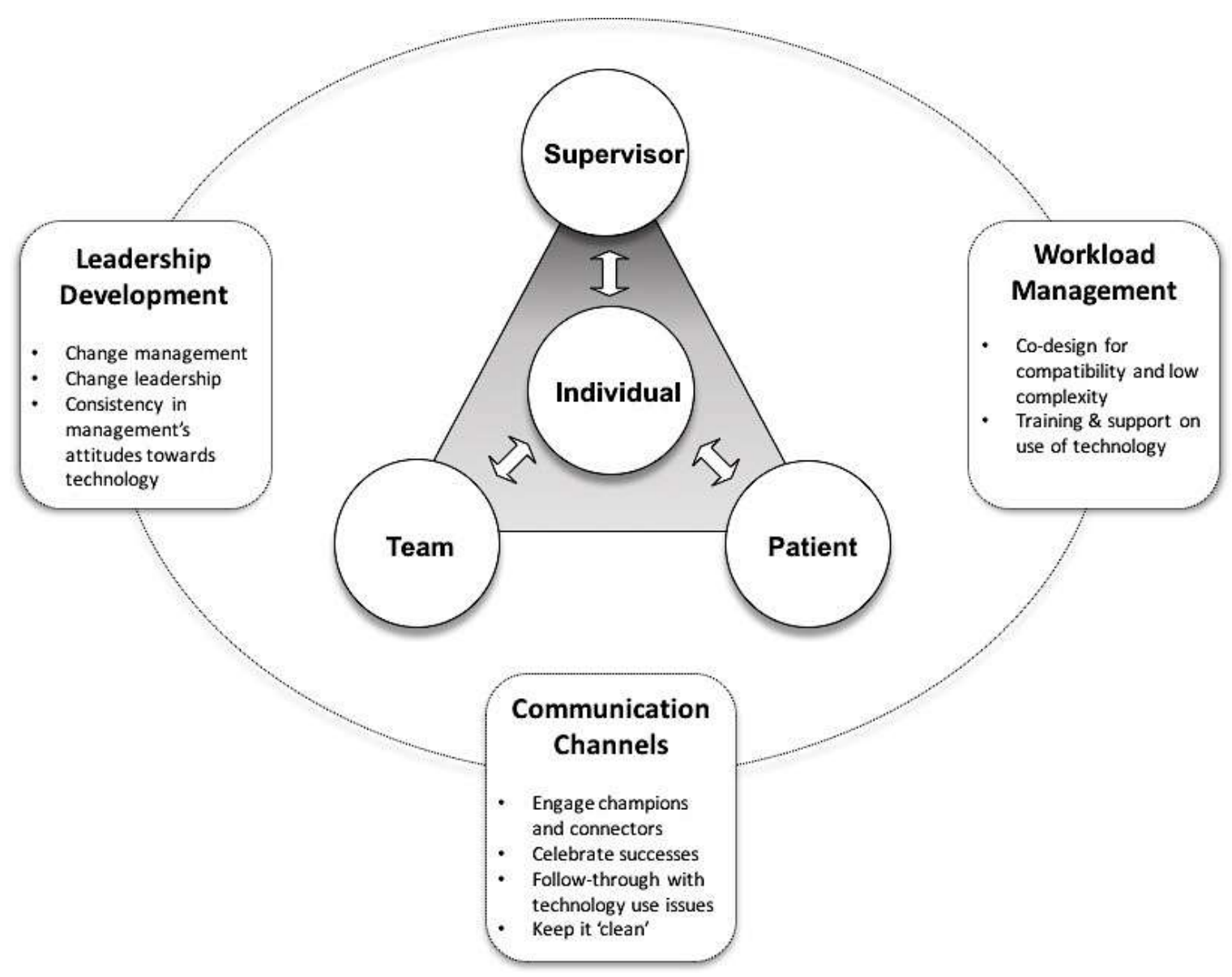

Figure 3. The Tech-ISM Framework for medical decision-makers to drive innovation adoption in healthcare.

To sustain the momentum for adoption during the implementation of new technology, medical decision-makers must be prepared to address and remove barriers and routinely celebrate incremental successes (Kotter, 1995). Both formal and informal communication channels can be utilised as a medium for staff to raise issues and for medical decision-makers to provide feedback and support. Unit-wide surveys can be an effective mean of gathering information quickly and widely (Chase et al., 2008), while reflective debrief sessions facilitated by supervisory staff for their team members can be a more personable approach for voicing 


\section{TECHNOLOGY ADOPTION IN HEALTHCARE DELIVERY}

feedback and concerns (Bailie et al., 2020). As insight on how the new technology works within local hospital contexts grow, so does its transparency, which helps instill staff trust and confidence in the technology and increase compliance (Chase et al., 2008). Celebrating the initial successes and benefits experienced by early adopters, teams, and change champions can further reinforce the social value of the technology, thereby increasing the motivation to adopt for others in the workplace (Kotter, 1995; Rogers et al., 2014). Offering continuous training for the new technology and access to technology developers, in contrast to one-off training and access at the start, can be helpful for when technology is updated or when there are new incoming staff members during the implementation period (Buonocore, 2004).

Of course, communication channels are of limited use if it is one-sided (i.e., top-down) and staff — particularly those lower in the healthcare hierarchy (Atwal \& Caldwell, 2005; Reese et al., 2016; Schwappach \& Gehring, 2014) — do not feel they can speak up about adoption challenges. It is the responsibility of medical decision-makers, healthcare management, and supervisory staff (Attree, 2007) to maintain two-way communications by fostering a sense of collaboration and psychological safety in healthcare workplaces (Chase et al., 2008). Medical decision-makers should set the standard that raising concerns is a professional duty to contribute to a culture of learning, and is respected, valued, and supported as so by hospital administration, policies, and senior staff (Attree, 2007; Aydon et al., 2016; Churchman \& Doherty, 2010; Garon, 2012).

Part of upholding psychological safety from a senior staff level is to encourage that all contributions are appreciated (Nembhard \& Edmondson, 2006) and to ensure issues raised are attended to within a reasonable timeframe (Adelman, 2012; Garon, 2012; Yanchus et al., 2014), which can help minimise the likelihood of negative adoption attitudes generating and spreading. This participation can provide staff with a sense of control and ownership of the new technology (Chase et al., 2008), and can lead to greater likelihood of acceptance of the 


\section{TECHNOLOGY ADOPTION IN HEALTHCARE DELIVERY}

new technology (Gagné et al., 2000; Rafferty \& Jimmieson, 2010; Rafferty \& Restubog, 2010). As well, medical decision-makers should work to keep the information within communication channels 'clean' - which means setting expectations for unacceptable or uncivil behaviours that intentionally spread negative adoption attitudes (e.g., lobbying, smear campaign; (Felblinger, 2009)) and processes for mediating any conflict aggravated by the stress of new technology introduction.

\section{When Does the Work Start?}

Much of points discussed so far is not just relevant to the technology implementation period, but are characteristics that make up a well-functioning and happy healthcare workplace that requires effort and time to establish. For instance, while we suggested several ways to foster and uphold psychological safety around technology challenges in healthcare workplaces, much of general psychological safety is determined by the quality of relationships within the workplace within healthcare teams, across healthcare teams, and between team members and their leaders (O'Donovan \& McAuliffe, 2020). Similarly, issues underlying incivility, such as hierarchy and differences in experiences and philosophies towards care, typically set roots long before the implementation of technology, and are exacerbated by the introduction of new technology. Policies (Blake, 2016; Hoffman \& Chunta, 2015), interventions (e.g., civility education training programs; (Leiter et al., 2012; Leiter et al., 2011)), and preventative measures such as attempts to reduce hierarchy (e.g., shared decision-making (Lachman, 2014); interprofessional collaborations (Carayon \& Gürses, 2005; Gurses \& Carayon, 2009; Sinuff et al., 2007), participatory leadership (Buonocore, 2004)) can help reduce mistreatment and improve work relationships.

Another significant avenue to invest in early is the genuine engagement of healthcare staff and patients in the design of new technology to ensure it is fit-for-purpose and for the local hospital unit environment (see (O'Kane et al., 2021) for a review). Fostering collaborative 


\section{TECHNOLOGY ADOPTION IN HEALTHCARE DELIVERY}

co-design relationships between technology developers and healthcare staff, patients, and their families during the development phase can minimize issues around compatibility and complexity, reduce workload, and increase a sense of ownership and buy-in during the implementation period (Bird et al., 2021; Laurance et al., 2014; Llopis \& D’este, 2016; Merito \& Bonaccorsi, 2007). Medical decision-makers can ensure this engagement by prioritising codevelopment of technology (Sehgal \& Gupta, 2019): briefing developers early on the context of their local hospital environment, cultural implications, and the unique needs of their medical personnel (Jagtap, 2020), allocating resources to set up consultations, trials, and feedback between clinical staff, patients, and developers (Chase et al., 2008; Wass \& Vimarlund, 2016), demonstrating professional commitment by embedding co-design strategy into hospital mission and values and demonstrating personal commitment by looking for opportunities to become involved themselves (Pirinen, 2016).

\section{Conclusion}

In summary, adopting new technology requires changes in behaviours, thoughts, and feelings around existing ways of working. Traditional cognitive-behavioural approaches to studying technology adoption focus on individual perspectives of technology, but overlook the powerful influence of peer attitudes and oversimplify the dynamic process of achieving systemwide adoption over time. Cognitive-behavioural approaches may not be appropriate for understanding technology adoption in the fast-paced, high-stakes, high-stress healthcare delivery work context, as teams are highly task and responsibility-interdependent, and depends on conformity and hierarchy to perform effectively and safely.

We proposed a social approach to understand technology adoption in healthcare. Specifically, how attitudes towards technology are generated and spread between individual staff and their team members, patients, and supervisory staff. These three types of social 


\section{TECHNOLOGY ADOPTION IN HEALTHCARE DELIVERY}

dynamics can be enhanced during the technology implementation period by effective formal and informal communication channels, reduction in staff workload, and developing leadership competencies of healthcare managers. Medical decision-makers should invest in these three areas, as well as manage the resources and work relationships leading up to and throughout the implementation period.

While implementing new technology may feel like an ambitious endeavor to medical decision-makers, healthcare organisations can utilise their defining strength of protocolisation to enable technology adoption to happen. We discussed the necessity for specific and responsive training as a resource that supports technology adoption, yet pro-technology attitudes, behaviours, and actions can be built into healthcare systems through deliberate plans and processes for technology uptake. Medical decision-makers could protocolise technology adoption for better patient outcomes (less mistakes) and more consistent innovation uptake, much as medicine has protocolised the delivery of care for the same reasons. 


\section{References}

Adelman, K. (2012). Promoting employee voice and upward communication in healthcare: The CEO's influence. Journal of healthcare management, 57(2), 133-147. https://doi.org/10.1097/00115514-201203000-00009

Adler-Milstein, J., Kvedar, J., \& Bates, D. W. (2014). Telehealth among US hospitals: several factors, including state reimbursement and licensure policies, influence adoption. Health Affairs, 33(2), 207-215.

Alexander, A., Garloch, K., \& Neff, J. (2012). Nonprofit hospitals thrive on profits. Charlotte Observer.

Ali, N. A., Mekhjian, H. S., Kuehn, P. L., Bentley, T. D., Kumar, R., Ferketich, A. K., \& Hoffmann, S. P. (2005). Specificity of computerized physician order entry has a significant effect on the efficiency of workflow for critically ill patients. Critical care medicine, 33(1), 110-114. https://doi.org/10.1097/01.CCM.0000150266.58668.F9

Allen, D. (2014). The invisible work of nurses: Hospitals, organisation and healthcare. https://doi.org/10.4324/9781315857794

Andreatta, P. B. (2010). A typology for health care teams. Health care management review, 35(4), 345-354. https://doi.org/10.1097/HMR.0b013e3181e9fceb

Apker, J., Propp, K. M., \& Zabava Ford, W. S. (2005). Negotiating Status and Identity Tensions in Healthcare Team Interactions: An Exploration of Nurse Role Dialectics. Journal of Applied Communication $\quad$ Research, 33(2), 93-115. https://doi.org/10.1080/00909880500044620

Attree, M. (2007). Factors influencing nurses' decisions to raise concerns about care quality. Journal of nursing management, 15(4), 392-402. https://doi.org/10.1111/j.13652834.2007.00679.x 


\section{TECHNOLOGY ADOPTION IN HEALTHCARE DELIVERY}

Atwal, A., \& Caldwell, K. (2005). Do all health and social care professionals interact equally: a study of interactions in multidisciplinary teams in the United Kingdom. Scandinavian journal of caring sciences, 19(3), 268-273. https://doi.org/10.1111/j.14716712.2005.00338.x

Aydon, L., Hauck, Y., Zimmer, M., \& Murdoch, J. (2016). Factors influencing a nurse's decision to question medication administration in a neonatal clinical care unit. Journal of clinical nursing, 25(17-18), 2468-2477. https://doi.org/10.1111/jocn.13277

Bailie, J., Laycock, A. F., Peiris, D., Bainbridge, R. G., Matthews, V., Cunningham, F. C., Conte, K. P., Abimbola, S., Passey, M. E., \& Bailie, R. S. (2020). Using developmental evaluation to enhance continuous reflection, learning and adaptation of an innovation platform in Australian Indigenous primary healthcare. Health research policy and systems, 18(1), 45-45. https://doi.org/10.1186/s12961-020-00562-4

Baker, L., Egan-Lee, E., Martimianakis, M. A., \& Reeves, S. (2011). Relationships of power: implications for interprofessional education. Journal of interprofessional care, 25(2), 98-104.

Bakerjian, D. (2008). Care of nursing home residents by advanced practice nurses: A review of the literature. Research in gerontological nursing, 1(3), 177-185.

Bandura, A., \& McClelland, D. (1971). Social learning theory. Motivational trends in society

Barsade, S. G., \& Gibson, D. E. (2007). Why does affect matter in organizations? Academy of management perspectives, 21(1), 36-59.

Bartel, C. A., \& Saavedra, R. (2000). The collective construction of work group moods. Administrative Science Quarterly, 45(2), 197-231.

Baumol, W. J. (2012). The cost disease. Yale university press. 


\section{TECHNOLOGY ADOPTION IN HEALTHCARE DELIVERY}

Bird, M., McGillion, M., Chambers, E. M., Dix, J., Fajardo, C. J., Gilmour, M., Levesque, K., Lim, A., Mierdel, S., Ouellette, C., Polanski, A. N., Reaume, S. V., Whitmore, C., \& Carter, N. (2021, 2021

2021-03-19). A generative co-design framework for healthcare innovation: development and application of an end-user engagement framework. Research Involvement and Engagement, 7, 1-12. https://doi.org/http://dx.doi.org/10.1186/s40900-021-00252-7

Blake, N. (2016). Building respect and reducing incivility in the workplace: Professional standards and recommendations to improve the work environment for nurses. $A A C N$ advanced critical care, 27(4), 368-371. https://doi.org/10.4037/aacnacc2016291

Bogerd, M. J., Slottje, P., Schellevis, F. G., Giebels, A., Rijken, M., van Hout, H. P., \& Reinders, M. E. (2019). From protocolized to person-centered chronic care in general practice: study protocol of an action-based research project (COPILOT). Primary health care research \& development, 20.

Bonawitz, K., Wetmore, M., Heisler, M., Dalton, V. K., Damschroder, L. J., Forman, J., Allan, K. R., \& Moniz, M. H. (2020). Champions in context: which attributes matter for change efforts in healthcare? Implementation science, 15(1), 1-10.

Bono, J. E., \& Ilies, R. (2006). Charisma, positive emotions and mood contagion. The Leadership quarterly, 17(4), 317-334. https://doi.org/10.1016/j.leaqua.2006.04.008

Bordia, P., Hunt, E., Paulsen, N., Tourish, D., \& DiFonzo, N. (2004). Uncertainty during organizational change: Is it all about control? European Journal of Work and $\begin{array}{lll}\text { Organizational } & \text { Psychology, } & \text { 345-365. }\end{array}$ https://doi.org/10.1080/13594320444000128

Breakwell, G. M. (1988). Strategies adopted when identity is threatened. Revue internationale de psychologie sociale.

Breakwell, G. M. (2015). Coping with threatened identities. Psychology Press. 


\section{TECHNOLOGY ADOPTION IN HEALTHCARE DELIVERY}

Brooks, H., Sanders, C., Lovell, K., Fraser, C., \& Rogers, A. (2015). Re-inventing care planning in mental health: stakeholder accounts of the imagined implementation of a user/carer involved intervention. BMC health services research, 15(1), 1-12.

Brown, J., Lewis, L., Ellis, K., Stewart, M., Freeman, T. R., \& Kasperski, M. J. (2011). Conflict on interprofessional primary health care teams-can it be resolved? Journal of interprofessional care, 25(1), 4-10.

Buonocore, D. (2004). Leadership in action: creating a change in practice. AACN clinical issues, 15(2), 170-181. https://doi.org/10.1097/00044067-200404000-00002

Cairns, G., de Andrade, M., \& MacDonald, L. (2013). Reputation, relationships, risk communication, and the role of trust in the prevention and control of communicable disease: a review. Journal of health communication, 18(12), 1550-1565.

Carayon, P., \& Gürses, A. P. (2005). A human factors engineering conceptual framework of nursing workload and patient safety in intensive care units. Intensive \& critical care nursing, 21(5), 284-301. https://doi.org/10.1016/j.iccn.2004.12.003

Carrez, L., Bouchoud, L., Fleury, S., Combescure, C., Falaschi, L., Sadeghipour, F., \& Bonnabry, P. (2019). Work overload is related to increased risk of error during chemotherapy preparation. Journal of oncology pharmacy practice, 25(6), 1456-1466. https://doi.org/10.1177/1078155219845432

Chase, J. G., Andreassen, S., Jensen, K., \& Shaw, G. M. (2008). Impact of human factors on clinical protocol performance: a proposed assessment framework and case examples

Chase, J. G., Shaw, G. M., Preiser, J.-C., Knopp, J. L., \& Desaive, T. (2021). Risk-Based Care: Let's Think Outside the Box. Frontiers in medicine, 8, 535244-535244. https://doi.org/10.3389/fmed.2021.535244 


\section{TECHNOLOGY ADOPTION IN HEALTHCARE DELIVERY}

Chaudoir, S. R., Dugan, A. G., \& Barr, C. H. (2013). Measuring factors affecting implementation of health innovations: a systematic review of structural, organizational, provider, patient, and innovation level measures. Implementation science, 8(1), 1-20.

Cho, Y., Hwang, J., \& Lee, D. (2012). Identification of effective opinion leaders in the diffusion of technological innovation: A social network approach. Technological Forecasting and Social Change, 79(1), 97-106.

Churchman, J. J., \& Doherty, C. (2010). Nurses' views on challenging doctors' practice in an acute hospital. Nursing standard, 24(40), 42-47. https://doi.org/10.7748/ns2010.06.24.40.42.c7830

Ciechanowski, P. S., Katon, W. J., Russo, J. E., \& Walker, E. A. (2001). The patient-provider relationship: attachment theory and adherence to treatment in diabetes. American Journal of Psychiatry, 158(1), 29-35.

Clark, D., Dean, G., Bolton, S., \& Beeson, B. (2019). Bench to bedside: the technology adoption pathway in healthcare. Health and Technology, 1-9.

Coz Yataco, A., Jaehne, A. K., \& Rivers, E. P. (2017). Protocolized Early Sepsis Care Is Not only Helpful for Patients: It Prevents Medical Errors. Critical care medicine, 45(3), 464-472. https://doi.org/10.1097/CCM.0000000000002237

Davis, F. D. (1989). Perceived usefulness, perceived ease of use, and user acceptance of information technology. MIS quarterly, 319-340.

Dimoff, J. K., \& Kelloway, E. K. (2019). With a little help from my boss: The impact of workplace mental health training on leader behaviors and employee resource utilization. Journal of occupational health psychology, 24(1), 4.

Dimova, R., Stoyanova, R., \& Doykov, I. (2018). Mixed-methods study of reported clinical cases of undesirable events, medical errors, and near misses in health care. Journal of evaluation in clinical practice, 24(4), 752-757. 


\section{TECHNOLOGY ADOPTION IN HEALTHCARE DELIVERY}

Duggal, A., Panitchote, A., Siuba, M., Krishnan, S., Torbic, H., Hastings, A., Mehkri, O., Hanane, T., Hatipoglu, U., Hite, R. D., \& Mireles-Cabodevila, E. (2021). Implementation of Protocolized Care in ARDS Improves Outcomes. Respiratory care, 66(4), 600-609. https://doi.org/10.4187/respcare.07999

Eastman, D., \& McCarthy, C. (2012). Embracing change: Healthcare technology in the 21st century. The Journal of Excellence in Nursing Leadership, 43(6), 52-54.

Edmondson, A. (1999). Psychological Safety and Learning Behavior in Work Teams. Administrative Science Quarterly, 44(2), 350-383. https://doi.org/10.2307/2666999

Facts \& Factors (2021, April 14, 2021). Global Healthcare in IT Market Size \& Share Will Grow to USD 662 Billion by 2026: Facts \& Factors. https://www.globenewswire.com/news-release/2021/04/14/2210138/0/en/GlobalHealthcare-in-IT-Market-Size-Share-Will-Grow-to-USD-662-Billion-by-2026-FactsFactors.html

Felblinger, D. M. (2009). Bullying, incivility, and disruptive behaviors in the healthcare setting: identification, impact, and intervention. Frontiers of health services management, 25(4), 13-23. https://doi.org/10.1097/01974520-200904000-00003

Foulk, T., Woolum, A., \& Erez, A. (2016). Catching rudeness is like catching a cold: The contagion effects of low-intensity negative behaviors. Journal of Applied Psychology, 101(1), 50.

Gagné, M., Koestner, R., \& Zuckerman, M. (2000). Facilitating acceptance of organizational change: The importance of self-determination 1. Journal of applied social psychology, 30(9), 1843-1852.

Gagnon, M.-P., Desmartis, M., Labrecque, M., Car, J., Pagliari, C., Pluye, P., Frémont, P., Gagnon, J., Tremblay, N., \& Légaré, F. (2012). Systematic review of factors 


\section{TECHNOLOGY ADOPTION IN HEALTHCARE DELIVERY}

influencing the adoption of information and communication technologies by healthcare professionals. Journal of medical systems, 36(1), 241-277.

Garber, S., Gates, S. M., Keeler, E. B., Vaiana, M. E., Mulcahy, A. W., Lau, C., \& Kellermann, A. L. (2014). Redirecting innovation in US health care: options to decrease spending and increase value. Rand health quarterly, 4(1).

Gardezi, F., Lingard, L., Espin, S., Whyte, S., Orser, B., \& Baker, G. R. (2009). Silence, power and communication in the operating room. Journal of advanced nursing, 65(7), 13901399. https://doi.org/10.1111/j.1365-2648.2009.04994.x

Garon, M. (2006). The positive face of resistance: nurses relate their stories. JONA: The Journal of Nursing Administration, 36(5), 249-258.

Garon, M. (2012). Speaking up, being heard: registered nurses' perceptions of workplace communication. Journal of nursing management, 20(3), 361-371. https://doi.org/10.1111/j.1365-2834.2011.01296.x

George, J. M., \& Jones, G. R. (2001). Towards a process model of individual change in organizations. Human relations, 54(4), 419-444.

Gergerich, E., Boland, D., \& Scott, M. A. (2019). Hierarchies in interprofessional training. Journal of interprofessional care, 33(5), 528-535.

Gill, R. (2002). Change management--or change leadership? Journal of change management, 3(4), 307-318.

Glass, R., \& Li, S. (2010). Social influence and instant messaging adoption. Journal of Computer Information Systems, 51(2), 24-30.

Glorioso, V., \& Subramanian, S. (2014). Equity in access to health care services in Italy. Health services research, 49(3), 950-970. 


\section{TECHNOLOGY ADOPTION IN HEALTHCARE DELIVERY}

Goodwin, M., Ito, K., Gupta, A. H., \& Rivers, E. P. (2016). Protocolized care for early shock resuscitation. Current opinion in critical care, 22(5), 416-423. https://doi.org/10.1097/MCC.0000000000000346

Grant, A. M., Curtayne, L., \& Burton, G. (2009). Executive coaching enhances goal attainment, resilience and workplace well-being: a randomised controlled study. The journal of positive psychology, 4(5), 396-407. https://doi.org/10.1080/17439760902992456

Green, B., Oeppen, R., Smith, D. a., \& Brennan, P. (2017). Challenging hierarchy in healthcare teams-ways to flatten gradients to improve teamwork and patient care. British Journal of Oral and Maxillofacial Surgery, 55(5), 449-453.

Greenhalgh, T., Robert, G., Macfarlane, F., Bate, P., \& Kyriakidou, O. (2004). Diffusion of Innovations in Service Organizations: Systematic Review and Recommendations. The Milbank quarterly, 82(4), 581-629. https://doi.org/10.1111/j.0887-378X.2004.00325.x

Greenhalgh, T., \& Stones, R. (2010). Theorising big IT programmes in healthcare: strong structuration theory meets actor-network theory. Social science \& medicine, 70(9), $1285-1294$.

Greenhalgh, T., Wherton, J., Papoutsi, C., Lynch, J., Hughes, G., Hinder, S., Fahy, N., Procter, R., \& Shaw, S. (2017). Beyond adoption: a new framework for theorizing and evaluating nonadoption, abandonment, and challenges to the scale-up, spread, and sustainability of health and care technologies. Journal of medical Internet research, 19(11), e367.

Grol, R. (2001, Aug). Successes and failures in the implementation of evidence-based guidelines for clinical practice. Med Care, $39(8$ Suppl 2), II46-54. https://doi.org/10.1097/00005650-200108002-00003

Gurses, A. P., \& Carayon, P. (2009). Exploring performance obstacles of intensive care nurses. Applied ergonomics, 40(3), 509-518. https://doi.org/10.1016/j.apergo.2008.09.003 


\section{TECHNOLOGY ADOPTION IN HEALTHCARE DELIVERY}

Halpern, N. A. (2009). Can the costs of critical care be controlled? Current opinion in critical care, $15(6), 591-596$.

Hao, H., Padman, R., Sun, B., \& Telang, R. (2018). Quantifying the impact of social influence on the information technology implementation process by physicians: A hierarchical Bayesian learning approach. Information systems research, 29(1), 25-41.

Hatfield, E., \& Cacioppo, J. (1994). Emotional contagion. New York: Cambridge University Press ISBN 0-521-44948-0.

Ministry of Health (2019, 18 November 2020). Annual Update of Key Results 2018/19: New Zealand Health Survey. https://www.health.govt.nz/publication/annual-update-keyresults-2018-19-new-zealand-health-survey

Health, S. (2020, Jul 1, 2020 ). StartUp Health's 2020 Midyear Funding Report Shows a Robust, Diversified Health Innovation Market. https://healthtransformer.co/startuphealths-2020-midyear-funding-report-shows-a-robust-diversified-health-innovationmarket-8ecd7cfd968d

Hoffman, R. L., \& Chunta, K. (2015). Workplace Incivility: Promoting Zero Tolerance in Nursing. Journal of radiology nursing, 34(4), 222-227. https://doi.org/10.1016/j.jradnu.2015.09.004

Hollenbeck, J. R., Beersma, B., \& Schouten, M. E. (2012). BEYOND TEAM TYPES AND TAXONOMIES: A DIMENSIONAL SCALING CONCEPTUALIZATION FOR TEAM DESCRIPTION. The Academy of Management review, 37(1), 82-106. https://doi.org/10.5465/amr.2010.0181

Holt, D. T., Armenakis, A. A., Feild, H. S., \& Harris, S. G. (2007). Readiness for organizational change: The systematic development of a scale. The Journal of applied behavioral science, 43(2), 232-255. 


\section{TECHNOLOGY ADOPTION IN HEALTHCARE DELIVERY}

Hughes, A. M., Gregory, M. E., Joseph, D. L., Sonesh, S. C., Marlow, S. L., Lacerenza, C. N., Benishek, L. E., King, H. B., \& Salas, E. (2016). Saving Lives: A Meta-Analysis of Team Training in Healthcare. Journal of Applied Psychology, 101(9), 1266-1304. https://doi.org/10.1037/apl0000120

Ingebrigtsen, T., Georgiou, A., Clay-Williams, R., Magrabi, F., Hordern, A., Prgomet, M., Li, J., Westbrook, J., \& Braithwaite, J. (2014). The impact of clinical leadership on health information technology adoption: systematic review. International journal of medical informatics, 83(6), 393-405.

Jager, A. J. M. A., Tutty, M. A. P., \& Kao, A. C. M. D. P. (2016). Association Between Physician Burnout and Identification With Medicine as a Calling. Mayo Clinic proceedings, 92(3), 415-422. https://doi.org/10.1016/j.mayocp.2016.11.012

Jagtap, S. (2020). BARRIERS AND ENABLERS IN CO-DESIGNING WITH MARGINALISED PEOPLE. Proceedings of the Design Society: DESIGN Conference,

Jones, F., Poestges, H., \& Brimicombe, L. (2016). Building bridges between healthcare professionals, patients and families: a coproduced and integrated approach to selfmanagement support in stroke. NeuroRehabilitation, 39(4), 471-480.

Jones, S. (2014). Distributed leadership: A critical analysis. Leadership (London, England), 10(2), 129-141. https://doi.org/10.1177/1742715011433525

Kaasalainen, S., Ploeg, J., Donald, F., Coker, E., Brazil, K., Martin-Misener, R., Dicenso, A., \& Hadjistavropoulos, T. (2015). Positioning clinical nurse specialists and nurse practitioners as change champions to implement a pain protocol in long-term care. Pain Management Nursing, 16(2), 78-88.

Kaluza, A. J., Boer, D., Buengeler, C., \& van Dick, R. (2020). Leadership behaviour and leader self-reported well-being: A review, integration and meta-analytic examination. Work and stress, 34(1), 34-56. https://doi.org/10.1080/02678373.2019.1617369 


\section{TECHNOLOGY ADOPTION IN HEALTHCARE DELIVERY}

Kim, S., Bochatay, N., Relyea-Chew, A., Buttrick, E., Amdahl, C., Kim, L., Frans, E., Mossanen, M., Khandekar, A., \& Fehr, R. (2017). Individual, interpersonal, and organisational factors of healthcare conflict: a scoping review. Journal of interprofessional care, 31(3), 282-290.

Ko, M., Wagner, L., \& Spetz, J. (2018). Nursing home implementation of health information technology: Review of the literature finds inadequate investment in preparation, infrastructure, and training. INQUIRY: The Journal of Health Care Organization, Provision, and Financing, 55, 0046958018778902.

Koivunen, M., \& Saranto, K. (2018). Nursing professionals' experiences of the facilitators and barriers to the use of telehealth applications: a systematic review of qualitative studies. Scandinavian journal of caring sciences, 32(1), 24-44.

Kotter, J. P. (1995). Leading change: Why transformation efforts fail.

Kozlowski, D., Hutchinson, M., Hurley, J., Rowley, J., \& Sutherland, J. (2017). The role of emotion in clinical decision making: An integrative literature review. BMC medical education, 17(1), 255-255. https://doi.org/10.1186/s12909-017-1089-7

Kruse, C. S., Kristof, C., Jones, B., Mitchell, E., \& Martinez, A. (2016). Barriers to electronic health record adoption: a systematic literature review. Journal of medical systems, $40(12), 1-7$.

Kubr, M. (1996). Management consulting. A Guide to the Profession, 3.

Lachman, V. D. (2014). Ethical issues in the disruptive behaviors of incivility, bullying, and horizontal/lateral violence. Medsurg nursing, 23(1), 56-60.

Lamm, R. (1988). Health care as economic cancer. The Journal of medical practice management: $M P M, 4(2), 91-96$. 


\section{TECHNOLOGY ADOPTION IN HEALTHCARE DELIVERY}

Laurance, J., Henderson, S., Howitt, P. J., Matar, M., Al Kuwari, H., Edgman-Levitan, S., \& Darzi, A. (2014). Patient engagement: four case studies that highlight the potential for improved health outcomes and reduced costs. Health Affairs, 33(9), 1627-1634.

LeBlanc, V. R., McConnell, M. M., \& Monteiro, S. D. (2015). Predictable chaos: a review of the effects of emotions on attention, memory and decision making. Advances in health sciences education : theory and practice, 20(1), 265-282. https://doi.org/10.1007/s10459-014-9516-6

Lee, Y., Kozar, K. A., \& Larsen, K. R. (2003). The technology acceptance model: Past, present, and future. Communications of the Association for information systems, 12(1), 50.

Legris, P., Ingham, J., \& Collerette, P. (2003). Why do people use information technology? A critical review of the technology acceptance model. Information \& management, 40(3), 191-204.

Leiter, M. P., Day, A., Oore, D. G., \& Spence Laschinger, H. K. (2012). Getting Better and Staying Better: Assessing Civility, Incivility, Distress, and Job Attitudes One Year After a Civility Intervention. Journal of occupational health psychology, 17(4), 425434. https://doi.org/10.1037/a0029540

Leiter, M. P., Laschinger, H. K. S., Day, A., \& Oore, D. G. (2011). The Impact of Civility Interventions on Employee Social Behavior, Distress, and Attitudes. Journal of Applied Psychology, 96(6), 1258-1274. https://doi.org/10.1037/a0024442

Levenson, R. W. (1996). Biological substrates of empathy and facial modulation of emotion: Two facets of the scientific legacy of John Lanzetta. Motivation and Emotion, 20(3), 185-204.

Liberati, E. G., Ruggiero, F., Galuppo, L., Gorli, M., González-Lorenzo, M., Maraldi, M., Ruggieri, P., Friz, H. P., Scaratti, G., \& Kwag, K. H. (2017). What hinders the uptake 


\section{TECHNOLOGY ADOPTION IN HEALTHCARE DELIVERY}

of computerized decision support systems in hospitals? A qualitative study and framework for implementation. Implementation science, 12(1), 1-13.

Little, A. (2021, 21 April 2021). Building a New Zealand Health Service that works for all New Zealanders. $\quad$ https://www.nzdoctor.co.nz/sites/default/files/2021-04/Speeches\%20\%20HDSR.PDF

Llopis, O., \& D'este, P. (2016). Beneficiary contact and innovation: The relation between contact with patients and medical innovation under different institutional logics. Research Policy, 45(8), 1512-1523.

Lluch, M. (2011). Healthcare professionals' organisational barriers to health information technologies-A literature review. International journal of medical informatics, 80(12), 849-862.

Loewenstein, G. F., Weber, E. U., Hsee, C. K., \& Welch, N. (2001). Risk as feelings. Psychological bulletin, 127(2), 267.

Maitlis, S., \& Christianson, M. (2014). Sensemaking in organizations: Taking stock and moving forward. Academy of Management Annals, 8(1), 57-125.

Malloy, D. C., Hadjistavropoulos, T., McCarthy, E. F., Evans, R. J., Zakus, D. H., Park, I., Lee, Y., \& Williams, J. (2009). Culture and Organizational Climate: Nurses’ Insights Into Their Relationship With Physicians. Nursing ethics, 16(6), 719-733. https://doi.org/10.1177/0969733009342636

Marcum, J. A. (2013). The role of emotions in clinical reasoning and decision making. The Journal of medicine and philosophy, 38(5), 501-519. https://doi.org/10.1093/jmp/jht040

Marriott, L., \& Sim, Dalice. (2014, August 2014). Indicators of Inequality for Māori and Pacific People. https://www.wgtn.ac.nz/cpf/publications/working-papers/workingpaper-pdfs/WP09_2014_Indicators-of-Inequality.pdf 


\section{TECHNOLOGY ADOPTION IN HEALTHCARE DELIVERY}

May, C., \& Finch, T. (2009). Implementing, embedding, and integrating practices: an outline of normalization process theory. Sociology, 43(3), 535-554.

May, C., Finch, T., Mair, F., Ballini, L., Dowrick, C., Eccles, M., Gask, L., MacFarlane, A., Murray, E., \& Rapley, T. (2007). Understanding the implementation of complex interventions in health care: the normalization process model. BMC health services research, 7(1), 1-7.

May, C. R., Cummings, A., Girling, M., Bracher, M., Mair, F. S., May, C. M., Murray, E., Myall, M., Rapley, T., \& Finch, T. (2018). Using normalization process theory in feasibility studies and process evaluations of complex healthcare interventions: a systematic review. Implementation science, 13(1), 1-27.

McBride-Henry, K., \& Foureur, M. (2007). A secondary care nursing perspective on medication administration safety. Journal of advanced nursing, 60(1), 58-66. https://doi.org/10.1111/j.1365-2648.2007.04378.x

McGinn, C. A., Grenier, S., Duplantie, J., Shaw, N., Sicotte, C., Mathieu, L., Leduc, Y., Légaré, F., \& Gagnon, M.-P. (2011). Comparison of user groups' perspectives of barriers and facilitators to implementing electronic health records: a systematic review. $B M C$ medicine, 9(1), 1-10.

Mckenzie, K. B., \& Locke, L. A. (2014). Distributed Leadership: A Good Theory but what if Leaders Won't, Don't Know How, or Can't Lead? Journal of School Leadership, 24(1), 164-188.

Merito, M., \& Bonaccorsi, A. (2007). Co-evolution of physical and social technologies in clinical practice: The case of HIV treatments. Research Policy, 36(7), 1070-1087.

Miller, K., Joseph, L., \& Apker, J. (2000). Strategic ambiguity in the role development process. Journal of Applied Communication Research, 28(3), 193-214. https://doi.org/10.1080/00909880009365571 


\section{TECHNOLOGY ADOPTION IN HEALTHCARE DELIVERY}

Miskelly, P., \& Duncan, L. (2014). 'I'm actually being the grown-up now': leadership, maturity and professional identity development. Journal of nursing management, 22(1), 38-48.

Moore, G. C., \& Benbasat, I. (1991). Development of an Instrument to Measure the Perceptions of Adopting an Information Technology Innovation. Information systems research, 2(3), 192-222. https://doi.org/10.1287/isre.2.3.192

Moray, N. (2000). Culture, politics and ergonomics. Ergonomics, 43(7), 858-868.

Morris, A. H. (2003). Treatment algorithms and protocolized care. Current opinion in critical care, 9(3), 236-240.

Murray, E., Treweek, S., Pope, C., MacFarlane, A., Ballini, L., Dowrick, C., Finch, T., Kennedy, A., Mair, F., O'Donnell, C., Ong, B. N., Rapley, T., Rogers, A., \& May, C. (2010). Normalisation process theory: A framework for developing, evaluating and implementing complex interventions. BMC medicine, 8(1), 63-63. https://doi.org/10.1186/1741-7015-8-63

Nembhard, I. M., \& Edmondson, A. C. (2006). Making it safe: the effects of leader inclusiveness and professional status on psychological safety and improvement efforts in health care teams. Journal of organizational behavior, 27(7), 941-966. https://doi.org/10.1002/job.413

Ness, K., \& Klass, R. (1994). Risk perception by patients with anxiety disorders. Journal of.

Newton, J. M., Henderson, A., Jolly, B., \& Greaves, J. (2015). A contemporary examination of workplace learning culture: An ethnomethodology study. Nurse education today, 35(1), 91-96. https://doi.org/10.1016/j.nedt.2014.07.001

O'Donovan, R., \& McAuliffe, E. (2020). A systematic review of factors that enable psychological safety in healthcare teams. International journal for quality in health care, 32(4), 240-250. https://doi.org/10.1093/intqhc/mzaa025 


\section{TECHNOLOGY ADOPTION IN HEALTHCARE DELIVERY}

O'Kane, C., Haar, J., Mangematin, V., Daellenbach, U., \& Davenport, S. (2021). Distilling and renewing science team search through external engagement. Research Policy, 50(6), 104261.

Ortega, A., Van den Bossche, P., Sánchez-Manzanares, M., Rico, R., \& Gil, F. (2014). The Influence of Change-Oriented Leadership and Psychological Safety on Team Learning in Healthcare Teams. Journal of business and psychology, 29(2), 311-321. https://doi.org/10.1007/s10869-013-9315-8

Ozanne, U. B., \& Churchill Jr, G. A. (1971). Five dimensions of the industrial adoption process. Journal of Marketing Research, 8(3), 322-328.

Pearson, C. M., \& Clair, J. A. (1998). Reframing Crisis Management. The Academy of Management review, 23(1), 59-76. https://doi.org/10.2307/259099

Pescosolido, A. T. (2002). Emergent leaders as managers of group emotion. The Leadership quarterly, 13(5), 583-599.

Pirinen, A. (2016). The barriers and enablers of co-design for services. International Journal of Design, 10(3), 27-42.

Pitama, S., Huria, T., \& Lacey, C. (2014). Improving Māori health through clinical assessment: Waikare o te Waka o Meihana. New Zealand Medical Journal, 127(1393), 107-119.

Pitama, S., Robertson, P., Cram, F., Gillies, M., Huria, T., \& Dallas-Katoa, W. (2007). Meihana Model: A Clinical Assessment Framework. New Zealand Journal of Psychology, 36(3).

Prochaska, J. O., \& Velicer, W. F. (1997). The transtheoretical model of health behavior change. American journal of health promotion, 12(1), 38-48. https://doi.org/10.4278/0890-1171-12.1.38

Radin Umar, R. Z., Sommerich, C. M., Lavender, S. A., Sanders, E., \& Evans, K. D. (2018). Conceptual frameworks for the workplace change adoption process: elements 


\section{TECHNOLOGY ADOPTION IN HEALTHCARE DELIVERY}

integration from decision making and learning cycle process. Ergonomics, 61(9), 11731186. https://doi.org/10.1080/00140139.2018.1475016

Rafferty, A. E., \& Jimmieson, N. L. (2010). Team change climate: A group-level analysis of the relationships among change information and change participation, role stressors, and well-being. European Journal of Work and Organizational Psychology, 19(5), 551586.

Rafferty, A. E., Jimmieson, N. L., \& Armenakis, A. A. (2013). Change readiness: A multilevel review. Journal of management, 39(1), 110-135.

Rafferty, A. E., \& Restubog, S. L. D. (2010). The impact of change process and context on change reactions and turnover during a merger. Journal of management, 36(5), 13091338.

Reese, J., Simmons, R., \& Barnard, J. (2016). Assertion Practices and Beliefs Among Nurses and Physicians on an Inpatient Pediatric Medical Unit. Hospital pediatrics, 6(5), 275281.

Reichers, A. E., Wanous, J. P., \& Austin, J. T. (1997). Understanding and managing cynicism about organizational change. Academy of management perspectives, 11(1), 48-59.

Robinson, M. R., Daniel, L. C., O’Hara, E. A., Szabo, M. M., \& Barakat, L. P. (2014). Insurance status as a sociodemographic risk factor for functional outcomes and healthrelated quality of life among youth with sickle cell disease. Journal of pediatric hematology/oncology, 36(1), 51.

Rogers, E. M., Singhal, A., \& Quinlan, M. M. (2014). Diffusion of innovations. Routledge.

Salas, E., Grossman, R., Hughes, A. M., \& Coultas, C. W. (2015). Measuring team cohesion: Observations from the science. Human factors, 57(3), 365-374. 


\section{TECHNOLOGY ADOPTION IN HEALTHCARE DELIVERY}

Sanchez-Burks, J., \& Huy, Q. N. (2009). Emotional Aperture and Strategic Change: The Accurate Recognition of Collective Emotions. Organization science (Providence, R.I.), 20(1), 22-34. https://doi.org/10.1287/orsc.1070.0347

Schipper, L. G., Van Hulst, L. T., Grol, R., Van Riel, P. L., Hulscher, M. E., \& Fransen, J. (2010). Meta-analysis of tight control strategies in rheumatoid arthritis: protocolized treatment has additional value with respect to the clinical outcome. Rheumatology, 49(11), 2154-2164.

Schreiweis, B., Pobiruchin, M., Strotbaum, V., Suleder, J., Wiesner, M., \& Bergh, B. (2019). Barriers and facilitators to the implementation of ehealth services: systematic literature analysis. Journal of medical Internet research, 21(11), e14197.

Schuster, M. A., McGlynn, E. A., \& Brook, R. H. (2005). How Good Is the Quality of Health Care in the United States? The Milbank quarterly, 83(4), 843-895. https://doi.org/10.1111/j.1468-0009.2005.00403.x

Schwappach, D. L., \& Gehring, K. (2014). Trade-offs between voice and silence: A qualitative exploration of oncology staff's decisions to speak up about safety concerns. BMC health services research, 14(1), 303-303. https://doi.org/10.1186/1472-6963-14-303

Seashore, S. E. (1954). Group cohesiveness in the industrial work group. University of Michigan Ann Arbor.

Sehgal, S., \& Gupta, G. (2019). Converging resources and co-producing for innovation: evidence from healthcare services. European Journal of Innovation Management.

Shah, E. D., \& Rothstein, R. I. (2020). Crossing the chasm: tools to define the value of innovative endoscopic technologies to encourage adoption in clinical practice. Gastrointestinal endoscopy, 91(5), 1183-1186.

Sinuff, T., Cook, D., Giacomini, M., Heyland, D., \& Dodek, P. (2007). Facilitating clinician adherence to guidelines in the intensive care unit: A multicenter, qualitative study. 
TECHNOLOGY ADOPTION IN HEALTHCARE DELIVERY

Critical care $\quad$ medicine, 2083-2089. https://doi.org/10.1097/01.ccm.0000281446.15342.74

Sommaruga, M., Casu, G., Giaquinto, F., \& Gremigni, P. (2017). Self-perceived provision of patient centered care by healthcare professionals: The role of emotional intelligence and general self-efficacy. Patient education and counseling, 100(5), 974-980.

Sommer, S. A., Howell, J. M., \& Hadley, C. N. (2016). Keeping Positive and Building Strength: The Role of Affect and Team Leadership in Developing Resilience During an Organizational Crisis. Group \& organization management, 41(2), 172-202. https://doi.org/10.1177/1059601115578027

Spehar, I., Frich, J. C., \& Kjekshus, L. E. (2015). Professional identity and role transitions in clinical managers. Journal of health organization and management.

Statista. (2018). Total global medical technology revenue from 2011 to 2024. https://www.statista.com/statistics/325809/worldwide-medical-technology-revenue/

Steigenberger, N. (2015). Emotions in sensemaking: a change management perspective. Journal of Organizational Change Management.

Sundqvist, A. S., \& Carlsson, A. A. (2014). Holding the patient's life in my hands: S wedish registered nurse anaesthetists' perspective of advocacy. Scandinavian journal of caring sciences, 28(2), 281-288.

Sundstrom, E., De Meuse, K. P., \& Futrell, D. (1990). Work Teams: Applications and Effectiveness. The American psychologist, 45(2), 120-133. https://doi.org/10.1037/0003-066X.45.2.120

Sy, T., Côté, S., \& Saavedra, R. (2005). The Contagious Leader: Impact of the Leader's Mood on the Mood of Group Members, Group Affective Tone, and Group Processes. Journal of Applied Psychology, 90(2), 295-305. https://doi.org/10.1037/0021-9010.90.2.295 


\section{TECHNOLOGY ADOPTION IN HEALTHCARE DELIVERY}

Tang, Z., Weavind, L., Mazabob, J., Thomas, E. J., Chu-Weininger, M. Y. L., \& Johnson, T. R. (2007). Workflow in intensive care unit remote monitoring: A time-and-motion study. Critical care medicine, 35(9), 2057-2063. https://doi.org/10.1097/01.CCM.0000281516.84767.96

Taplin, S. H., Weaver, S., Chollette, V., Marks, L. B., Jacobs, A., Schiff, G., Stricker, C. T., Bruinooge, S. S., \& Salas, E. (2015). Teams and teamwork during a cancer diagnosis: Interdependency within and between teams. Journal of oncology practice, 11(3), 231238. https://doi.org/10.1200/JOP.2014.003376

Todorova, I. L. G., Alexandrova-Karamanova, A., Panayotova, Y., \& Dimitrova, E. (2014). Organizational hierarchies in Bulgarian hospitals and perceptions of justice. British journal of health psychology, 19(1), 204-218. https://doi.org/10.1111/bjhp.12008

Torrente, P., Salanova, M., \& Llorens, S. (2013). Spreading engagement: On the role of similarity in the positive contagion of team work engagement. Revista de Psicología del Trabajo y de las Organizaciones, 29(3), 153-159.

Totterdell, P. (2000). Catching moods and hitting runs: Mood linkage and subjective performance in professional sport teams. Journal of Applied Psychology, 85(6), 848.

Totterdell, P., Kellett, S., Teuchmann, K., \& Briner, R. B. (1998). Evidence of mood linkage in work groups. Journal of Personality and Social Psychology, 74(6), 1504.

Trafimow, D., \& Sheeran, P. (1998). Some tests of the distinction between cognitive and affective beliefs. Journal of experimental social psychology, 34(4), 378-397.

Triberti, S., \& Riva, G. (2015). Engaging users to design positive technologies for patient engagement: the perfect interaction model. patient engagement: a consumer-centered model to innovate healthcare. Berlin: De Gruyter Open, 56-65. 


\section{TECHNOLOGY ADOPTION IN HEALTHCARE DELIVERY}

Vaidyanathan, G., Sankaranarayanan, R., \& Yap, N. T. (2019). Bridging the chasm-Diffusion of energy innovations in poor infrastructure starved communities. Renewable and Sustainable Energy Reviews, 99, 243-255.

van Deen, W. K., Cho, E. S., Pustolski, K., Wixon, D., Lamb, S., Valente, T. W., \& Menchine, M. (2019). Involving end-users in the design of an audit and feedback intervention in the emergency department setting-a mixed methods study. BMC health services research, 19(1), 1-13.

Vautier, M. (2019, 23 Sep 2019). Global medtech revenues reach all-time high, yet innovation investments lag. https://www.ey.com/en_nz/news/2019/09/global-medtech-revenuesreach-all-time-high-yet-innovation-investments-lag

Venkatesh, V., \& Davis, F. D. (2000). A theoretical extension of the technology acceptance model: Four longitudinal field studies. Management science, 46(2), 186-204.

Venkatesh, V., Morris, M. G., Davis, G. B., \& Davis, F. D. (2003). User acceptance of information technology: Toward a unified view. MIS quarterly, 425-478.

Vikström, S., \& Johansson, K. (2019). Professional pride: A qualitative descriptive study of nursing home staff's experiences of how a quality development project influenced their work. Journal of clinical nursing, 28(15-16), 2760-2768. https://doi.org/10.1111/jocn.14884

Wanous, J. P., Reichers, A. E., \& Austin, J. T. (2000). Cynicism about Organizational Change: Measurement, Antecedents, and Correlates. Group \& organization management, 25(2), 132-153. https://doi.org/10.1177/1059601100252003

Wass, S., \& Vimarlund, V. (2016). Healthcare in the age of open innovation-a literature review. Health Information Management Journal, 45(3), 121-133.

Weick, K. E. (1995). Sensemaking in organizations (Vol. 3). Sage. 


\section{TECHNOLOGY ADOPTION IN HEALTHCARE DELIVERY}

Westover, J. H. (2010). Managing organizational change: Change agent strategies and techniques to successfully managing the dynamics of stability and change in organizations. International Journal of Management and Innovation, 2(1), 45-51.

Whelan-Berry, K. S., Gordon, J. R., \& Hinings, C. R. (2003). Strengthening Organizational Change Processes: Recommendations and Implications from a Multilevel Analysis. The Journal of applied behavioral science, 39(2), 186-207. https://doi.org/10.1177/0021886303256270

Wildman, J. L., Thayer, A. L., Rosen, M. A., Salas, E., Mathieu, J. E., \& Rayne, S. R. (2012). Task Types and Team-Level Attributes: Synthesis of Team Classification Literature. Human resource development review, 11(1), 97-129. https://doi.org/10.1177/1534484311417561

Woods, P. A., Bennett, N., Harvey, J. A., \& Wise, C. (2004). Variabilities and Dualities in Distributed Leadership: Findings from a Systematic Literature Review. Educational management, administration \& leadership, 32(4), 439-457. https://doi.org/10.1177/1741143204046497

Wutzke, S., Benton, M., \& Verma, R. (2016). Towards the implementation of large scale innovations in complex health care systems: views of managers and frontline personnel. BMC research notes, 9(1), 1-5.

Yanchus, N. J., Derickson, R., Moore, S. C., Bologna, D., \& Osatuke, K. (2014). Communication and psychological safety in veterans health administration work environments. Journal of health organization and management, 28(6), 754-776. https://doi.org/10.1108/JHOM-12-2012-0241 